\title{
Just a Fantasy? Examining Fantasy Sport in a Time Without Sport
}

\author{
Brody J. Ruihley and Jacob Chamberlin \\ Miami University, Oxford
}

\begin{abstract}
The fantasy sport industry has seen tremendous growth over the past three decades. Estimated at 500,000 participants in 1988, the industry has had positive growth every step of the way to a current estimate of 59.3 million North American participants. Touting this incredible rise in participation, nothing has obstructed the growth of this sport media and communication phenomenon until now. The sport landscape and fantasy sport industry find themselves in a situation with complete absence of live sport. The Coronavirus crisis has impacted the fantasy sport community and thousands of professionals in many ways. This research commentary, supplemented with primary interview data, questions the stoppage of fantasy sport and explores conversations, planning, and reaction from the fantasy sport community.
\end{abstract}

Keywords: Coronavirus, COVID-19, gaming

The fantasy sport industry has seen tremendous growth over the past three decades. Estimated at 500,000 North American participants in 1988, the industry has had positive growth every step of the way to a current estimate of 59.3 million participants (Fantasy Sports \& Gaming Association, 2020). It has become one of the biggest sport media, gaming, and communication phenomenon. The industry has won lawsuits over the right to use sport statistics and game results, shrugged off early legal associations to sport gambling, survived player strikes and work stoppages, and lobbied in nearly every U.S. state for the right to offer daily fantasy sport product (hereinafter referred to DFS). Nothing had stopped this activity from growing, expanding, and providing entertainment to millions of sport fans ... until now. Seemingly, the only way to stop fantasy sport play is not having sport. The initial impact of the Coronavirus crisis of 2020 created a social-distancing environment not suitable for sport participation and spectator viewing. This sport closure has impacted the fantasy sport community in ways that were and are far beyond anyone's imagination. With major sports like professional soccer, basketball, hockey, football, golf, and racing all in season, this is arguably the best time of the American sport calendar and the worst time for all sport to

The authors are with Miami University, Oxford, OH, USA. Ruihley (brody.ruihley@miamioh.edu) is corresponding author. 
stop. This shutdown has affected thousands of fantasy sport professionals, halted current fantasy sport play, and altered preparation for upcoming seasons.

This commentary explores fantasy sport operation in a critical time with no sport offerings and is supplemented with primary data collected from 13 fantasy sport professionals from organizations consisting of ESPN, Yahoo!, USA Today, The Athletic, and representatives from the Fantasy Sports \& Gaming Association (hereinafter referred to as FSGA) and Fantasy Sports Writers Association. Upon Miami University institutional review board approval, participants were targeted via a personalized e-mail request or by social media messaging to invite fantasy sport professionals to participate. Participants were directed to an online questionnaire where they gave consent to participate in the interview and answered a series of open-ended questions. These questions inquired about actions, strategy, and conversations had before and during the stoppage of sport. In addition, questions were asked about preparation for the return of sporting events and any changes for future operation based on lessons learned during this crisis. Participants were asked for permission to link their names with their comments. Some chose not to have their name associated with their comments and with that their responses are reported in an anonymized form. This commentary focuses on the reaction, response, and planning of the fantasy sport industry before, during, and after the Coronavirus crisis and explores if fantasy sport is simply a fantasy during this difficult time.

\section{Worst-Case Scenario}

The fantasy sport industry primarily has had to prepare for two types of business obstructions prior to sport's cancellation and postponement due to COVID-19. The first type involves stoppage of business for legal reasons. For example, in 2006, fantasy sport operator CBC Distribution and Marketing, Inc. sued Major League Baseball Advanced Media to argue that players' promotion and marketing rights should not include real-time statistics, a valuable commodity in the fantasy sport environment. This lawsuit came as a result of Major League Baseball Advanced Media selectively choosing licensing partners and essentially shutting down any other organization not in that exclusive group. CBC Distribution and Marketing, Inc. won their lawsuit and saved many in the fantasy sport industry banking on the ability to use real-time statistics and information. If this had gone the opposite direction, many fantasy sport businesses would have been forced to delay or end their operation until agreements or partnerships could be made to secure licensing rights. Another example in the legal realm involves the DFS boom of 2015 sending many U.S. state legislators into a frenzy when trying to sort out the activity as gaming or gambling (or both). As a result, many states placed DFS activities on hold for months while legislation and lobbying took place in order for DFS to stand on safe legal ground. Major DFS operators such as DraftKings and FanDuel had to stop business in many U.S. states and simply wait through this difficult time in their growth.

The second type of work obstruction concerning fantasy sport organizations is player strikes and labor disputes. Having no games or live statistics takes the fans' interest away from the fantasy sport industry. Aside from the 1981 Major League Baseball (MLB) strike, where columnists actually began writing about modern 
rules of fantasy baseball helping launch its popularity (Nesbit \& King, 2009; Walker, 2006), there have been several player strikes, lockouts, and labor disputes in the history of sport that have caused significant concern for fantasy sport organizations (CNN Editorial Research, 2020). Most notably the 2012-2013 National Hockey League (NHL) lockout and 2011-2012 National Basketball Association (NBA) lockout caused the cancellation of hundreds of games. With a majority of fantasy sport play happening in American professional football, the 136-day (off-season) lockout between the National Football League (NFL) owners and players caused the fantasy sport industry to discuss and prepare for the then worst-case scenario of a delayed start or no season at all. With much celebration, the agreement was ratified nearly a month prior to the season start. These examples are impactful and important, but their punch does not hit as hard as the one from the Coronavirus crisis. Labor disputes are drawn out and take time to come to full boil as collectively bargained agreements have expiration dates and time to negotiate. In previous cases while DFS activities were shut down in certain states causing a major financial hit, businesses were still able to operate in many other states. When the Coronavirus directly touched the American sport landscape on March 11 at an NBA basketball game, within a matter of hours, sports came to a screeching halt. While one can argue that warning signs were abound, the severity and abruptness of this stoppage took most, if not all, off guard. How does one plan for that? How does one prepare for the one thing you need to have in business, live sport statistics, to be gone for an indefinite amount of time?

\section{Coronavirus Conversations and Contingency Plans}

Participants were asked to pull back the curtain and discuss any conversations and contingency planning they had within their organizations about the crisis prior to the postponement of all sport. Collectively, participants were aware of the Coronavirus situation, assuming some sort of change to the sport spectator environment, and many were preparing for a potential suspension of live sports. Every organization planned and reacted differently as the news of the virus seemingly changed by the hour. Nando Di Fino, managing editor for fantasy sports at The Athletic, admits to being "super planners" and developing contingency plans "when things started to bubble up a little bit in Italy" (N. Di Fino, personal communication, April 22, 2020). Fantasy Sports Writers Association president, fantasy sport writer and analyst Andy Behrens, discussed Yahoo!'s preparation stating that they discussed the possibility of delays and postponements, "but not with any specifics in terms of content planning [as] shutdowns hit within perhaps a day of any of us considering the possibility" (A. Behrens, personal communication, April 22, 2020). Similarly, ESPN fantasy sport editor Pierre Becquey describes the company's response leading to the first event being canceled stating, "None of us predicted how quickly it would happen. As more information became available, we discussed various scenarios and the appropriate actions in order to best serve our fantasy players" (P. Becquey, personal communication, May 5, 2020). Paul Charchian, former FSGA president and current member of the board of directors, stated that prior to the NBA halting their play, the FSGA had few conversations about the potential for disruption to the sporting environment. He indicated, 
None of our forecasts saw the sweeping severity or speed of the shutdown that emerged. At the time, we were worried about people being afraid to fly or congregate. Nobody suggested that people wouldn't be allowed to fly or congregate. We speculated about a possible disruption of the start of the MLB season and/or the end of the NBA regular season. We discussed how fantasy sports operators would determine winners of their season-long contests. And similarly, we discussed how sports betting operators would handle futures bets. (P. Charchian, personal communication, April 23, 2020)

Since fantasy sport organizations rely solely on live sport statistics, many had already been looking into alternative plans, but even the best plans can fall flat in the face of a situation where sport is shutdown suddenly.

Contingency planning for fantasy sport organizations can vary greatly depending on the type of product offered. In the case of planning around this crisis, those covering primarily the NFL have more time than those who have a stake in the NBA, NHL, or MLB. Similarly, individual sports such as golf, mixed martial arts, or racing have vastly different time frames, and the organizations associated with those sports may have more flexibility in their planning. Our participant's response surrounding their contingency plans illustrates how different planning can be in this trying time. Charchian asserts, "Honestly, I don't know any company that had a meaningful contingency plan in place pre-Gobert." Josh Moore, Owner/ CEO of 4 for4 Fantasy Football, shared a thought that many likely felt, "It all happened so fast. I think we were all thinking that sports would go on without fans, but then everything got cancelled all at once, which came as a bit of a shock" (J. Moore, personal communication, April 23, 2020). ESPN's Becquey says there was not much contingency planning in place as they "didn't expect it to get so bad that sports would be postponed or cancelled" (P. Becquey, personal communication, May 5, 2020). Those who did seem to have backup products in place began thinking about many possibilities. For example, Di Fino explains that The Athletic began to "shift our focus to writing on things surrounding fantasy." He included ideas of fantasy weather games, pop culture and entertainment pieces, and ideas that were different while still "serving the fantasy audience as much as we could." Their strategy focused on the consumer, as they created many "mailbag columns" to hear from the subscribers "instead of taking a lot of guesses" (N. Di Fino, personal communication, April 22, 2020). Other organizations spoke about their planning and concern revolving around a potential work stoppage in the NFL either because of a virus-related postponement or due to a "possible NFL lockout in 2020 or 2021" (Anonymous participant 1, personal communication, 2020).

While it was unlikely that any fantasy sport provider would predict and execute a perfectly planned contingency plan, this research has uncovered that many may have avoided catastrophic damage to their businesses by having important conversations and keeping track of the Coronavirus impact on the sporting landscape.

\section{During the Crisis}

In the past, there has been a shutdown of particular sports for short periods of time (Beck, 2011; CNN Editorial Research, 2020; McIntyre, 2011). What is 
unparalleled in this period of fantasy sport is a pause of all sports worldwide. With many professional sport leagues in hiatus, fantasy sport companies are making organizational decisions on what type of content to produce and fantasy sport games to offer, while managing feedback and reactions from consumers to keep them engaged. During the time Coronavirus cases began to increase in the United States and stay-at-home orders were issued, the contingency plans that these fantasy sport companies discussed were forced into action. One decision was what content could be provided to keep their readers engaged. USA Today's Gardner describes his experience stating that "major changes involved shifting some sports department writers and editors to the news department to help with Coronavirus-related stories and other news operations" (S. Gardner, personal communication, April 22, 2020). Other companies looked around the world to find leagues that were able to still offer games as many sport media, wagering, and fantasy sport organizations have indicated excitement in the return of the Korean Baseball Organization. The previous examples have impacted fantasy sport offerings.

\section{Fantasy Sport Offerings}

As fantasy sport professionals implement organizational changes, many had to explore other avenues or gaming products. In DFS, contests consisted of simulated games, where consumers can draft players in the video game, Madden, and then watch the game played on a specific YouTube channel. DraftKings, one of the largest companies offering DFS, has turned to the Korean Baseball Organization, table tennis, and reality TV shows (Sprung, 2020). Becquey mentions that ESPN even had to look to nonnormal sport leagues and television programming for their offerings. He comments,

We continue to run our "Streak" game, which allows players to pick between two options, usually the result of a sporting event. We can draw from worldwide competition still in play, such as Belorussian soccer, but we've also gotten creative with props from TV shows ranging from "The Price is Right" to "The Bachelor" and even lottery drawings. We've also had singleevent games around the WNBA and NFL drafts. (P. Becquey, personal communication, May 5, 2020)

More traditional fantasy sport offerings during this time center around the NFL. Greg Ambrosius, fantasy sports games director for SportsHub Technologies, believes that customers are enjoying still being able to participate in drafts. He claims, “... Football drafts are still solid as folks enjoy the diversion of drafting upcoming football teams with the hope that the NFL will play a full season" (G. Ambrosius, personal communication, May 4, 2020). Charchian is also focused on engaging customers through NFL-related content. He discusses the need to prepare for an upcoming NFL season. He explains,

My company is a startup during the heart of the COVID-19 crisis. We've had to scale back our plans for funding and hiring. Yet, we have to prepare under the assumption that the NFL season will go off as planned, so we're still developing our products. (P. Charchian, personal communication, April 23, 2020) 
As companies diversify the offerings they are providing, a big question is how customers are reacting to these changes. Sport fans have grown accustom to the fantasy sport experience and consuming games with teams and players for whom they have a stake in. The interviewees gave insight on how their customers have reacted to their current offerings.

\section{Reaction From Customers}

Many people around the world are either voluntarily or have been ordered to stay home. Social distancing is now a common term and handshakes may be a thing of the past. People are needing content and distraction. Fantasy sport has always been a welcomed part of people's lives and would be a fitting distraction in this time of social isolation. When asked about how they believed customers were taking a pivot of offerings, interviewees felt their customers were happy to still have some sort of sport content. Di Fino says, "people have been grateful that we're not being lazy, we're still turning out content, and we're not completely dropping fantasy sports to do pop culture stuff. It's been pretty nice to hear the feedback" (N. Di Fino, personal communication, April 22, 2020). The appreciation of sport content by customers, even without sport, is echoed by Behrens saying that at Yahoo!, "we've continued to produce a significant amount of content, some of it nostalgic or gimmicky. My general feeling is that our users enjoy any distraction we can give them, even without live games" (A. Behrens, personal communication, April 22, 2020). While customers have embraced this change, there is still a strong desire for a return of sport. In one fan survey conducted on ESPN, $65 \%$ of fans supported a return to sport even without fans. Furthermore, $53 \%$ of sport fans felt sorrow that no sports had a return date (Adler, 2020). This sadness about sport and longing for return is real, and as the fantasy sport industry awaits the return of the world's most popular leagues, there is still optimism around a return to sport even in a form that fans and industry members have not seen before.

\section{Response From the FSGA}

The FSGA has been the voice of the fantasy sport industry for over two decades and recently expanded its scope to include gaming and gambling organizations. In this unprecedented time of no sport, it can be argued that their voice is needed now more than ever. Charchian stresses that during this time of COVID-19, a major aim for the association is to "offer the guidance companies need to stay afloat during this time of low revenue" (P. Charchian, personal communication, April 23, 2020). To accomplish this, the FSGA has responded by updating their website, posting relevant news on social media, and offering free webinars. On the FSGA website, members can access resources such as financial and mental health resources (Fantasy Sports \& Gaming Association, 2020). The FSGA has also utilized social media and e-mail to keep their members updated on the latest from sport leagues and laws that affect their members companies. For example, on their Twitter and Facebook page, the FSGA posted a news article about sports being continued without fans and how that would look. The webinars that have been offered by the FSGA cover topics from how the fantasy sport industry moves forward and updates to the U.S. sport leagues, to advice on how members can solve business problems during the COVID-19 pandemic and 
how to handle shortened seasons. For members unable to attend the webinars, the FSGA has posted all of videos on their website.

\section{Future}

In a pandemic like the one presented with COVID-19, it is easy to look to the future as a way to get back to normal or even pick up right where many organizations left off. For much of the sport management conversations about the future, discussions revolve around questions of when, how, and what will sport look and feel like? For most fantasy sport providers, writers, and hosts, they only need one thing: live action. Fantasy sport needs pitches thrown, pucks saved, birdies delivered, and races to be won. Even, at the time of this writing, some sports were returning to action. The Ultimate Fighting Championship, NASCAR, Bundesliga, and many Asian baseball leagues began play with no audience and very little in-house production and commentary. With this, there are some areas of fantasy sport and DFS activities that can take place. For a large majority, however, baseball, basketball, and soccer need to resume play, and football needs to kick off without delay. Participants were asked about the conversations they have had with their coworkers and peers about a return of sport. For most, it is all about when. Knowing the when helps everyone prepare and strategize. The interviewees mentioned the idea of "ramping up" and organizing their producers, writers, and part-timers again (Anonymous participant 2, personal communication, 2020). Behrens brings up a much-forgotten point arguing that when restrictions ease, we might not experience a slow burn back into sport; rather, it could be an all-at-once scenario. He suggests,

When sports return, they will come roaring back. No doubt about that. We're going to need to be flexible in our approach to coverage, because we can't yet say when anything will return or where it will take place. It's at least possible that we may have the NBA and NHL concluding their seasons while the NFL and MLB are in-season, with all sports operating simultaneously. That would definitely require us to deploy our writers in new ways. (A. Behrens, personal communication, April 22, 2020)

Similarly, Di Fino says that his conversations are about keeping "a close eye" on all sport developments and proposals being discussed in the professional leagues. He adds that they have "mapped out several plans, so we'll be ready when something happens/is decided" (N. Di Fino, personal communication, April 22, 2020). In the world of sport, this is a true season of waiting. While waiting, it is impossible to not think, prepare, and plan for what the sports world may look and feel like when and if restrictions ease. The idea of if restrictions ease is an important idea to consider. This is something Gardner his colleagues at USA Today are discussing. Like others, he states that they are "trying to stay ahead of the various proposals that have been floated." But what is different about Gardner's comments is a last point he makes stating that "most of the overall conversations we're having right now surround what might happen if sports DON'T come back" (S. Gardner, personal communication, April 22, 2020).

Contingencies plans have turned into dealing with the worst-case scenario of sport not returning in the near future. If this happens, individual sports or activities that can be done while social distancing might have a rise in popularity. Areas like 
golf, NASCAR, fighting, esports, or sport simulations could potentially keep user entertained, but it could take time for users to adapt to this change. The COVID-19 crisis is arguably one of the greatest challenges that the fantasy sport industry has ever faced, and if sport does not return to some faction of normal, it is going to take innovation and consumer buy-in to unique offerings to overcome any deficit.

There will be an abundance of research studies and commentary dedicated to what people, organizations, and the sport industry learned during the time of a global pandemic. For this research, participants were asked during the pandemic, what future decisions might look like as a result of this experience. One of the questions participants were asked was: Knowing what you know now, is there anything that you would have done differently prior to the crisis taking full hold? Surprisingly, a large majority of the responses said they would have changed nothing knowing what they know now. Whether the disruption was being prepared thoroughly already or there preserving a reputation was taking place, participants agreed that this type of situation is/was so rare and unique, they would not have been able to do anything differently leading up to this crisis. In response to this question, one of the anonymous participants stated, "I don't think anyone envisioned a shutdown of sports everywhere globally. I thought the worst thing that would happen would be sports with no fans" (Anonymous participant 1, personal communication, 2020). Looking back on the beginning of the pandemic, the FSGA's Charchian did mention one thing he/the association could have done differently. He adds, "I would have used the FSGA's communication channels to urge companies to update their Terms of Service to cover their plans for a modified, shortened, or cancelled season" (P. Charchian, personal communication, April 23, 2020).

Moving forward with future business in mind, fantasy sport operators have much to think about in terms of seasons, content, and logistics of league play. As Behrens mentioned, when sport comes back, it will likely be in heavy doses and with altered calendars. The participants in this research were primarily focused on what constitutes a full season of fantasy sport play. Ambrosius discusses this topic as what to pay attention to once the crisis is over stating, "We will need to add language in our rules on what constitutes a full fantasy season to award prizes. We hadn't planned for seasons to be shortened by acts of nature" (G. Ambrosius, personal communication, May 4, 2020). Charchian echoes this sentiment about what a full season of place might look like:

We've given great thought to how our season-long fantasy products would work in a modified season. For example, we're establishing an 8-week minimum for a valid season. And those 8 weeks don't need to be contiguous. We're also updating our Terms of Service to allow us to modify our gameplay as needed to support a modified season. (P. Charchian, personal communication, April 23, 2020)

There is amplified importance in understanding what a modified season would look like because fantasy sport games are played by millions and millions of people. Drafts, prize funds, and multiyear commitments are often a part of fantasy sport play. Having the ability to shift a season, once it has started, or choose what weeks of play will count toward standings is an important feature for a fantasy sport product to have. This takes careful planning and specific instruction for game 
designers to follow as they create or edit a fantasy sport product. This type of planning will provide more flexibility in the event another crisis takes place, but what is not apparent is that this type of product update might be essential for this exact same virus, should occur in later part of 2020 and early 2021. Why is this sport time frame important to fantasy sport providers? Three letters. NFL.

\section{Conclusion}

It is a fair question to ask if fantasy sport operation is just a fantasy when there are no sports being played. While a fantasy can be defined as "the faculty or activity of imagining things, especially things that are impossible or improbable" (Lexico, 2020, para. 2), this research commentary argues that fantasy sport activities are not just fantasy during the Coronavirus crisis. It is true that there is some imagining taking place within the industry while trying to predict and prepare for sport's return. However, this imagining is not improbable or impossible as this definition would suggest. As previously stated, fantasy sport operators need only live sport statistics to offer their product. This industry is full of real people, real jobs, and real decisions that need to be discussed prior to the probable return of live sport. As this research would suggest, fantasy sport operations are still taking place in different forms, conversations, and plans. While all sports were postponed or canceled, some sports have found their way back to action, with the rest are planning for return in a heavily altered environment. Once sport is back to playing, many will find comfort, peace, and some normalcy in the reality of their fantasy sport experiences.

\section{References}

Adler, K. (2020, May 4). ESPN commissions coronavirus lockdown fan study. Retrieved from https://espnpressroom.com/us/press-releases/2020/05/espn-commissions-coronaviruslockdown-fan-study/

Beck, H. (2011, November 26). N.B.A. and players reach deal to end lockout. Retrieved from https://www.nytimes.com/2011/11/27/sports/basketball/nba-and-basketball-playersreach-deal-to-end-lockout.html

CNN Editorial Research. (2020, March 17). Pro sports lockouts and strikes fast facts. Retrieved from https://www.cnn.com/2013/09/03/us/pro-sports-lockouts-and-strikesfast-facts/index.html

Fantasy Sports \& Gaming Association. (2020). COVID-19 resources and information for the fantasy sports \& gaming industries. Retrieved from https://thefsga.org/covid-19/

Lexico. (2020, July 25). Fantasy. Retrieved from https://www.lexico.com/en/definition/ fantasy

McIntyre, B (2011). NFL lockout and how we got here: Timeline to a new CBA. Retrieved from https://www.sbnation.com/nfl/2011/7/25/2292223/nfl-lockout-labor-cba

Nesbit, T.M., \& King, K.A. (2009). The impact of fantasy football participation on NFL attendance. Atlantic Economic Journal, 38(1), 95-108. doi:10.1007/s11293-009-9202-x

Sprung, S. (2020, April 7). DraftKings digs deep to keep bettors interested, with major sports halted by Coronavirus. Retrieved from https://www.forbes.com/sites/shlomosprung/ 2020/04/07/draftkings-coronavirus-dfs-mlb-nba-nfl-nhl-gambling/\#1b668e014bf5

Walker, S. (2006). Fantasyland: A sportswriter's bid to win the world's most ruthless fantasy baseball league. New York, NY: Penguin. 